\title{
Anti-Microbial and Antioxidant Activity of Different Pycnocycla Bashagardiana Essential Oil
}

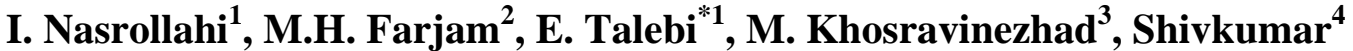 \\ ${ }^{1}$ Young Researchers and Elite Club, Darab Branch, Islamic Azad University, Darab, Fars, Iran \\ ${ }^{2}$ Department of Chemistry, Firoozabad Branch, Islamic Azad University, Firoozabad, Iran \\ ${ }^{3}$ Department of Chemistry, Shiraz Branch, Islamic Azad University, Shiraz, Iran \\ ${ }^{4}$ Central Sericultural Research and Training Institute, Central Silk Board, Pampore, Jammu \& \\ Kashmir, INDIA
}

\begin{abstract}
It is established fact that, the Pycnocycla bashagardiana a traditional endemic plant utilizing for its essential oil to several beneficial purposes are for flavoring materials, but very few work were done with regarding to its anti-bacterial and antioxidant activities. After extraction of essential oil from the plant, the GC and GC/MS analyses were used. The oil composition estimated in the identification of 22 compounds through both techniques. The Myristicin was recorded of 69.54\%. As well as, the E-Ocimene, Z-Ocimene and Methyleugenol were the main components by estimating of $21.04 \%, 9.24 \%$, and $4.70 \%$ respectively. The obtained results showed that the essential oil revealed the antimicrobial properties against gram-positive and gram-negative. It was also observed against gram-negative bacteria revealed high resistance and antifungal properties against fungus alternaria, for some extend over all, this essential oil revealed a high resistance to said respected organisms. Moreover, the antioxidant activity was performed by adopting the DPPH method, through which the Pycnocycla bashagardiana essential oil indicated highly significant radical scavenging antioxidant activity of IC $50=3.08 \pm 0.368 \mathrm{mg} / \mathrm{ml}$.
\end{abstract}

Keywords: Pycnocycla bashagardiana, HD, MAHD, Microwave, Antimicrobial, Antioxidant.

\section{INTRODUCTION}

Digesting the fact of scientific research methods and usage of different instrumental techniques takes a new avenue and will really helpful to resolve the intricate problems of any scientific research work as reported by several investigators. As for the understanding of numerous methods of extraction, content, antimicrobial and antioxidant activities of pharmaceutical plant's essential oil are concerned. The earlier traditional and conventional method for the extraction of essential oils is "hydro distillation" (HD), in which the essential oils are evaporated by heating a mixture of water and plant materials followed by the liquefaction of the vapors in a condenser. However, this method suffers from several disadvantages including losses in the volatile compounds, long extraction time and degradation of some components through thermal and hydrolytic effects [1]. Another, important method for extraction of essential oil from this plant is none other than "microwave- assisted hydro distillation" (MAHD), therein microwaves with HD were employed for the extraction of essential oils has also been considered. This method called microwave- assisted hydro distillation, where it is performed at atmospheric pressure using water as solvent so far. Moreover, Golmakani and Rezaei [2] were carried out the research by utilizing Zataria multiflora Boiss plant for subjecting different extraction methods including HD, MAHD, simultaneous distillation-solvent extraction (SDE) and supercritical fluid extraction. Apart, another main important reason for selecting these techniques was increased interest, because which lies in the much shorter operation times achievable and microwaveassisted extraction of natural compounds is also an alternative to conventional techniques. Essential oils are among the products which have been extracted efficiently from a variety of matrices by this method and many microwave-assisted essential oil extractions from several plants and subsequent product analyses have been reported [3,4]. The Pycnocycla bashagardiana (Umbelliferae) is an aromatic plant distributed in South parts of Iran [5,6]. But, most of its members are confined to northern temperate regions and high altitudes in the tropics. The species are commonly further distinguished by the presence of hollow stems and sheathing petioles and the leaves are nearly always 
alternate and pinnately or palmately compound or more than once compound; stipules are generally absent and the flowers are typically small and mostly bisexual [7]. The Pycnocycla bashagardiana essential oils are defined as natural compounds, which are obtained from aromatic plants. Nevertheless, they are volatile liquid, insoluble in water, highly soluble in alcohol, ether, vegetable and mineral oils and are complex mixture of different chemical compounds [5]. Nowadays, these essential oils are used as flavoring materials and in the preparation of perfumes and pharmaceutical products and are called "essential oils" [2]. Out of all species, the eight were established as endemic perennial species with spine leaves in Iran [8]. Moreover, they are traditionally and medicinally being used for the intestinal disorders and diarrhea [9]. Henceforth, digesting above all the literature's concepts, this research was selected by keeping main aim to compare the essential oil compounds obtained from HD and MAHD methods, total phenol and its anti-microbial and antioxidant properties in the extracted essential oil of Pycnocycla bashagardiana.

\section{Materials AND Methods}

All parts of the plant of P.Bashagardiana were collected during May 2014 in the Bashagardiana region of southern Iran (Bandar Abbas) and detected by Bahmani and maintaining all parts of the plant at room temperature $\left(25^{\circ} \mathrm{C}\right)$ were dried under shade standard laboratory condition at Medicinal Plants Research Institute, Islamic Azad University of Firozabad, Iran.

\subsection{Extraction of Essential Oil}

\subsubsection{Hydro Distillation Method}

The hydro distillation method was employed with some modification for the extraction of the essential oil and the extraction of oil was done from the plants using a Clevenger-type apparatus, where the plant material was subjected to hydro distillation. The Conditions of extraction were $70 \mathrm{~g}$ of all dried plant's parts and for instance leaf $350 \mathrm{ml}$ of distilled water left for $3 \mathrm{hrs}$ distillation. Then, anhydrous sodium sulphate was used for removing water after extraction and the extracted oil was kept in a refrigerator at $4^{\circ} \mathrm{C}[10]$.

\subsubsection{Microwave- Assisted Hydrodistillation Method}

Seventy gram of the aerial parts of the plant $P$. bashagardiana were powdered and subjected to hydro distillation, using a Clevenger-type apparatus for 2 hrs. Then, a typical microwave-assist hydro distillation procedure was performed at atmospheric pressure. The microwave oven was operated at 990W power levels for a period of 30 minutes, this period was sufficient to extract all the essential oils from the sample [11]. In a typical MAHD procedure performed at atmospheric pressure, $70 \mathrm{~g}$ of fresh plant material was heated using a fixed power of $600 \mathrm{~W}$ for 9 minutes without the addition of solvent or water. A cooling system outside the microwave cavity condensed the distillate continuously. Condensed water was refluxed into the extraction vessel in order to provide uniform conditions of temperature and humidity for the extraction. Finally, the extraction was continued at 100 ${ }^{\circ} \mathrm{C}$ until no more essential oil was obtained from the selected samples [12].

\subsubsection{GC and GC Mass}

Gas chromatographic and GC/MS analysis was carried out on a Perkin-Elmer 8500 gas chromatography with FID detector and a DB-1 capillary column $\left(30 \mathrm{~m}^{\prime} 0.25 \mathrm{~mm}\right.$, film thickness 0.25 $\mathrm{mm}$ ) (USA). The operating conditions were as follows: carrier gas helium with a flow rate of $2 \mathrm{~mL}$ for 1 minute with split ratio $1: 30$. The oven temperature was programmed 4 mini so thermal at $60^{\circ} \mathrm{C}$ and then $60-280{ }^{\circ} \mathrm{C}$ for 1 minute with injector and detector temperatures were set at $280{ }^{\circ} \mathrm{C}$ [13]. Further, the identification of the components was based on their GC retention indices (RI) on polar and nonpolar columns, determined relative to the retention time of a series of n-alkanes with linear interpolation with those of authentic compounds or literature data [14] and done through comparison of their mass spectra with the Wiley library [5].

\subsubsection{Microorganisms, Culture Media and Laboratory Conditions}

The microorganisms used in this experiment were Staphylococcus aureus (ATCC 1337 - grams positive), Klebseilla oxytoca (ATCC 1402 - gram-negative) and three fungal were examined namely Aspergilas niger (ATCC 5154), Fusarium solani (ATCC 5284) and Alternaria alternaria (ATCC 5224). All the microorganisms were prepared at Institute of Biological Research, Islamic Azad University, Firozabad, Iran. 


\subsection{Assessment of Antimicrobial Activity}

The antimicrobial activity was tested by using standard method of the broth dilution [15]. The inoculation of the microbial strains were prepared from the overnight broth cultures and suspensions were adjusted to $0.5 \mathrm{Mc}$ Farland standard turbidity (corresponding to 107-108 CFU/ml, depending on genera-consensus standard) [16]. Hundred $\mu \mathrm{L}$ of a suspension which containing approximately 108 $\mathrm{CFU} / \mathrm{mL}$ of each microorganism was spread on nutrient agar (NA). Further, six-millimeter diameter wells were cut from the agar using a sterile cork-borer, and $50 \mu \mathrm{L}$ of the oil solution in a concentration of $50 \mathrm{mg} / \mathrm{mL}$ (dissolved in DMSO) were delivered into the wells. The plates were incubated for 18 $24 \mathrm{hrs}$ at $37{ }^{\circ} \mathrm{C}$. Moreover, the antimicrobial activity was evaluated by measuring the zone of inhibition against the test organisms selected for present research [17].

\subsection{Determination of Minimum Inhibitory Concentration (MIC)}

Minimum inhibitory concentrations (MICs) determination was performed by a serial dilution technique using 96-well microtitreplates. The investigated essential oils $(0.01-10.00 \mu \mathrm{l} / \mathrm{ml})$ and main compounds $(0.001-0.010 \mathrm{ll} / \mathrm{ml})$ were added in a broth Tryptic Soy Broth (TSB) medium (bacteria) / broth Malt medium (fungi) with inoculum. The micro plates were incubated for $24 \mathrm{hrs}$ at $37{ }^{\circ} \mathrm{C}$ for bacteria and $72 \mathrm{hrs}$ at $28{ }^{\circ} \mathrm{C}$ for fungi respectively. Nevertheless, they were observed at lowest concentrations without visible growth (using the binocular microscope) were defined as MICs [18].

\subsection{Antioxidant Activity}

The antioxidant capacity of $P$. bashagardiana essential oil of the volatile aglycones was measured in terms of hydrogen donating or radical scavenging ability by using the stable radical, DPPH [19]. Wherein $20 \mu \mathrm{L}$ of the essential oil at different concentrations $(0.2-1 \mathrm{mg} / \mathrm{mL}$ ) or $\mathrm{MeOH}$ (control) were mixed with $200 \mu \mathrm{L}$ of 2, 2-diphenyl-1-picrylhydrazyl (DPPH) methanol solution ( $20 \mathrm{mg} / \mathrm{L})$. After 30 minutes incubation was done under darkness condition at ambient temperature and the absorbance was measured at $515 \mathrm{~nm}$. Butylated hydroxytoluene (BHT) and quercetin were used as positive controls, all analyses were carried out in triplicate and results were expressed as mean \pm SD. However, the percentage inhibition of the DPPH radical was calculated according to the formula described by Bouzidia et al. [20].

$$
\text { Percentage inhibition }(\% \mathrm{I})=[(\text { A blank }- \text { A sample }) / \text { A blank }] \times 100
$$

The IC50 value, which represented the concentrations of the essential oil and extracts that caused $50 \%$ inhibition was determined by linear regression analysis from the obtained RSC values [21].

\subsection{Assay for Total Phenolic Content}

The total phenolic constituents of the P. bashagardiana essential oil were determined using the popular literature methods in evolving Folin-Ciocalteu reagent and gallic acid as standard [22, 23]. Briefly, $500 \mu \mathrm{l}$ of plant oils dissolved in methanol $(1 \mathrm{mg} / \mathrm{ml})$ were mixed with $5 \mathrm{cc}$ of Folin-Ciocalteu reagent (diluted 10 times in distilled water) in glass tubes in triplicate. The samples were incubated at room temperature for 5 minutes and vortex mixed at least 2 times. Then, $4 \mathrm{cc}$ of $\mathrm{Na}_{2} \mathrm{CO}_{3} 7.5 \%$ was added and the glass tubes were incubated in the dark for 15 minutes with continuous shaking. The absorbances of samples were measured at $765 \mathrm{~nm}$ using a Spectrophotometer (Perkin-Elmer UV/Vis double beam lambda 1, USA) against a blank of distilled water [24].

\section{RESUlts AND DisCuSSION}

The results of the experiment obtained from essential oil P. bashagardiana with hydro distillation and microwave assist hydro distillation extraction methods were meticulously identified for the chemical composition of essential oil. The detection of chemical content and percentage obtained were carried out with the help of gas chromatography-mass spectrometry respectively. In this direction, the Table 1 clearly showed in detailed experiment results of the plant P. bashagardiana (Figures 2-4). There were totally KI values of 19140 was recorded from over all the 14 chemical compounds, among them the highest of 1666, 1657, 1603 and $1531 \mathrm{KI}$ values were recorded in $\beta$-Eudesmol, $\beta$-Eudesmol, Guaiac alcohol and myristicin respectively in the essential oil of P.bashagardiana (Figure-1). Further, the 11 combinations of chemical compounds were observed in the hydro distillation method and yielded the total essential oil of $97.96 \%$ (Figure-2). On the other hand, the microwave assist hydro distillation method herein also observed totally 11 different combinations and yielded the total essential oil of $99.90 \%$ (Figure-3). Moreover, by elaborating individual values recorded, out of all the 


\section{Nasrollahi et al.}

11 combinations, the most of the major respected compounds of Myristicin (69.54\%), (E)-Ocimene (21.04\%), Z-cimene (9.24\%) and Methyleugenol (4.70\%) were clearly observed in the essential oil of $P$. bashagardiana and their chemical compounds/formulae were represented and shown in Figure 4. However, the above results clearly corroborate with the results of Farjam et al. [25] and other few researchers in the Anvillea garcini essential oil plant. In their research also reported that, some of the compounds like myristicin, (E)-Ocimene, $\beta$-Eudesmol, etc were noticed as major compounds and similarly herein the present research also observed the highest values of chemical compounds both from the HD as well as the MAHD methods respectively. Furthermore, the grand total KI, HD\% and MAHD\% were clearly exhibited of 19140, 97.96 and 99.90 respectively.

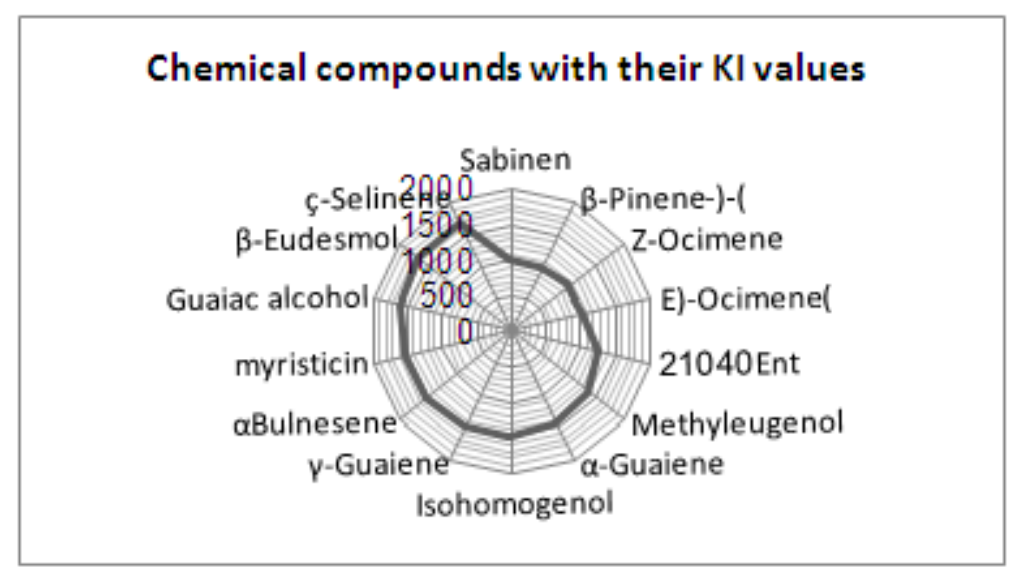

Figure1. Chemical compounds with their KI values obtained from the essential oil of P. bashagardiana

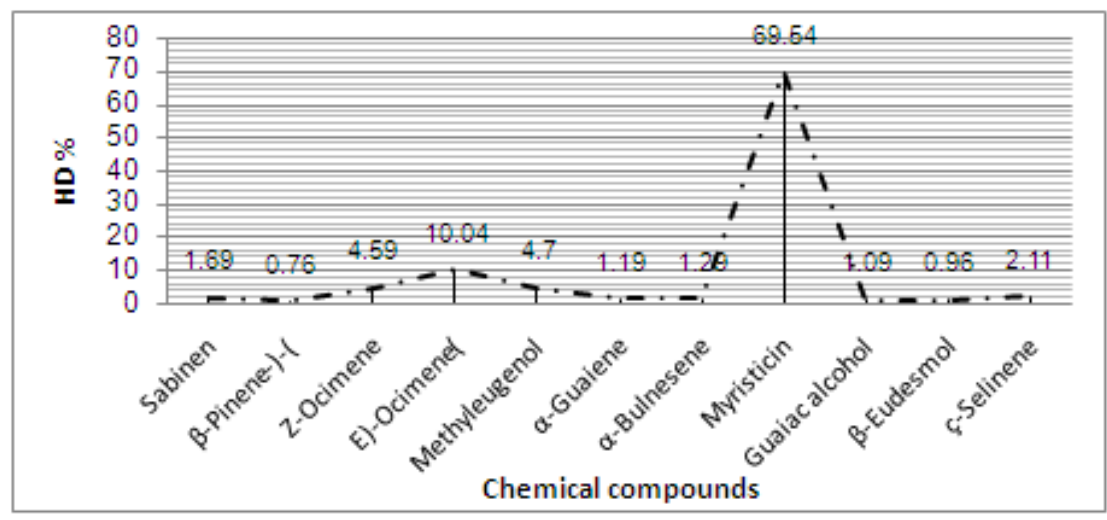

Figure2. The percentage of HD observed for 11 different chemical compounds in essential oil of $P$. bashagardiana

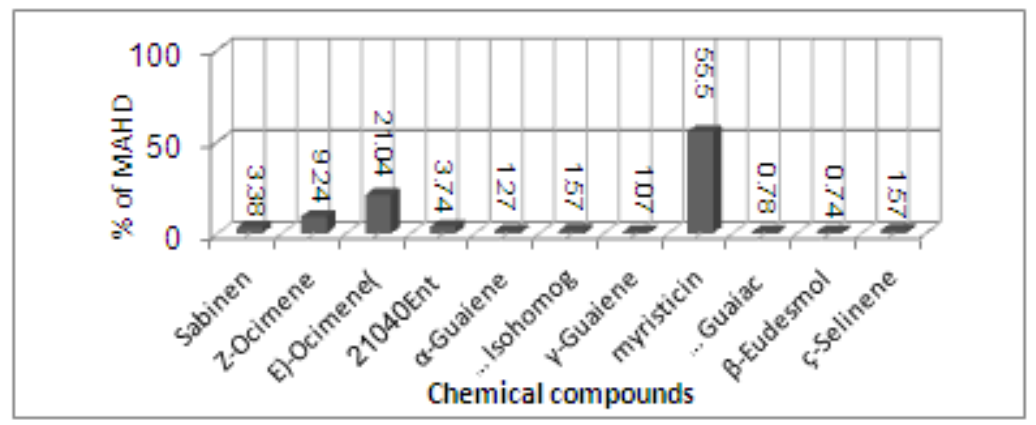

Figure3. The percentage of MAHD observed for 11 different chemical compounds in essential oil of $P$. bashagardiana

Table1. Chemical compounds obtained from the essential oil P. Bashagardiana through HD \& MAHD

\begin{tabular}{|c|c|c|c|c|}
\hline NO. & Compound & KI & HD\% & MAHD\% \\
\hline 1 & Sabinen & 974 & 1.69 & 3.38 \\
\hline 2 & (-)- $\beta$-Pinene & 978 & 0.76 & ----- \\
\hline 3 & Z-Ocimene & 1036 & 4.59 & 9.24 \\
\hline 4 & (E)-Ocimene & 1047 & 10.04 & 21.04 \\
\hline
\end{tabular}


Anti-Microbial and Antioxidant Activity of Different Pycnocycla Bashagardiana Essential Oil

\begin{tabular}{|c|c|c|c|c|}
\hline \hline 5 & Ent 21040 & 1269 & -------- & 3.74 \\
\hline 6 & Methyleugenol & 1416 & 4.70 & ------ \\
\hline 7 & $\alpha$-Guaiene & 1443 & 1.19 & 1.27 \\
\hline 8 & Isohomogenol & 1499 & ----- & 1.57 \\
\hline 9 & $\gamma$-Guaiene & 1510 & ----- & 1.07 \\
\hline 10 & $\alpha$ Bulnesene & 1511 & 1.29 & ----- \\
\hline 11 & myristicin & 1531 & 69.54 & 0.78 \\
\hline 12 & Guaiac alcohol & 1603 & 1.09 & 0.74 \\
\hline 13 & $\beta$-Eudesmol & 1657 & 0.96 & 1.57 \\
\hline 14 & c-Selinene & 1666 & 2.11 & $\mathbf{9 9 . 9 0}$ \\
\hline
\end{tabular}
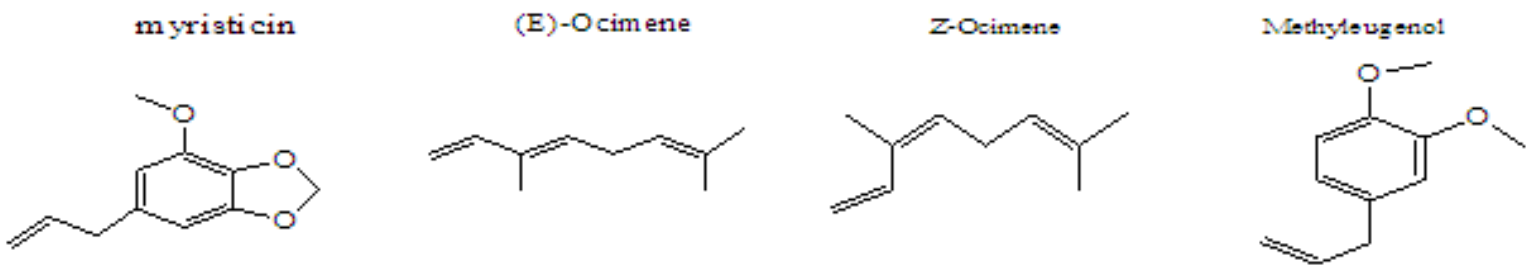

Figure4. Four major compounds of $P$. bashagardiana

\subsection{Antimicrobial Activity}

The antimicrobial effects of $P$. bashagardiana essential oil was tested and revealed against grampositive bacteria staphylococcus aureus with 256 unit $\mathrm{mg} / \mathrm{ml}$ and Klebseilla oxytoca exhibited gram negative with 64 unit $\mathrm{mg} / \mathrm{ml}$. Moreover, three fungal species namely, F. solani, A. niger and A. alternaria were also observed gram negative fungal effect of 64,16 and 08 unit $\mathrm{mg} / \mathrm{ml}$ respectively. However, corresponding solvents had no inhibitory effect on any of the tested microorganisms in the control treatment. The results of these tested organism as well as the effects of a control antibiotic are presented in Table 2 and same is represented as graph in Figure 5. The corroborating results were earlier detected by Asghari et al. [26], wherein they have reported similar results in the essential oil from the seeds of artemisia aucheri Boiss. Apart, Farjam et al. [25] and other researchers were conducted the experiment in Anvillea garcini essential oil plant and their results were clearly correlates with the results of the present experiment.

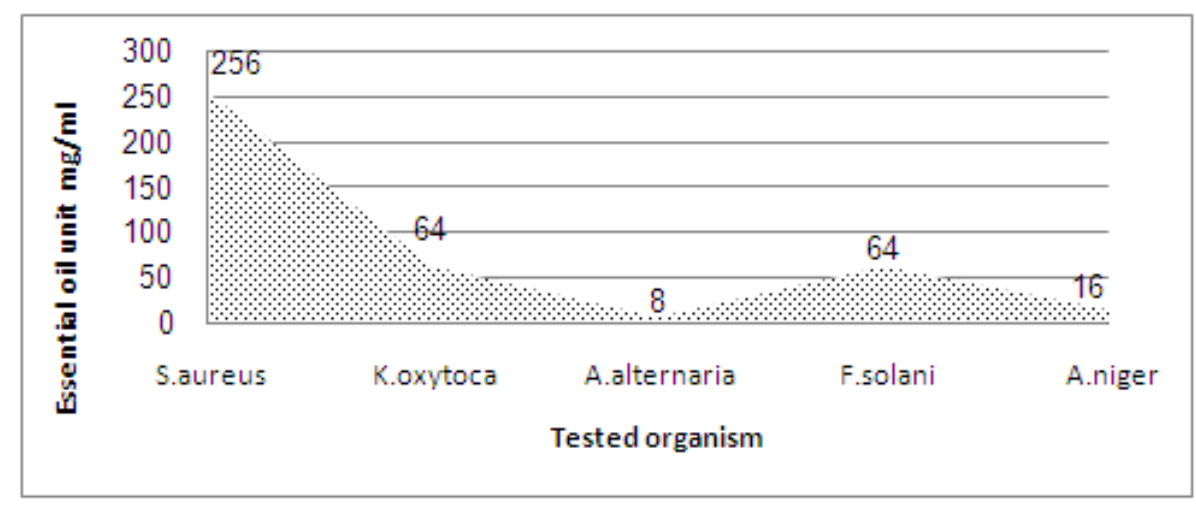

Figure5. Antimicrobial activity in essential oil of $P$. bashagardiana

Table2. Antimicrobial activity of essential oils of P. bashagardiana $(\mathrm{mg} / \mathrm{ml})$

\begin{tabular}{|c|c|c|c|c|c|}
\hline Tested organism & S. aureus & K. oxytoca & A. alternaria & F. solani & A. niger \\
\hline Essential oil & 256 & 64 & 8 & 64 & 16 \\
\hline
\end{tabular}

\subsection{Antioxidant and Total Phenol}

The DPPH assay is known to provide reliable information concerning the antioxidant capacity of specific compound or oil across a short time scale. The Huang et al. using Vitexnegundo Linn [27] and Farjam et al. [28] by n-butanolic extract in essential oil of Stachyspilifera were earlier worked on the antioxidant activity and results revealed similarity. Talebi et al. [29] were researched on phenolic content in Anvillea garcini essential oil plant and have reported the relevant results. Nevertheless, the current experiment was first determined by measuring the DPPH scavenging ability on plants 
essential oil of other species, but a very few research were done utilizing the $P$. bashagardiana and our present study therefore evolved in two various established methods to evaluate antioxidative activity of this oil, namely, DPPH radical-scavenging activity and total phenol antioxidant capacity and antioxidant activities of $P$. bashagardiana plant oil is DPPH IC50 $3.08 \pm 0.368(\mathrm{mg} / \mathrm{ml})$ and total phenolic content of $0.0083 \pm 0.0011$ were observed the selected plant oil and in detailed was given in Table- 3 and same is represented as graph in figure- 6 .

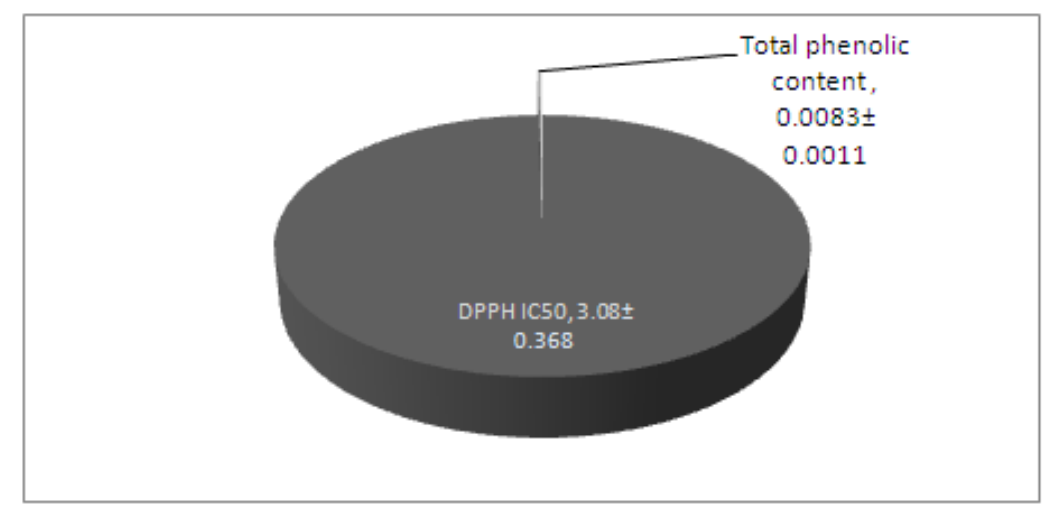

Figure6. Showing antioxidant activity and phenolic content in essential oil of P. bashagardiana

Table3. Antioxidant activity and total phenolic content of the essential oil P. bashagardiana

\begin{tabular}{|c|c|}
\hline DPPH IC50 (mg/ml) & Total phenolic content (mg/g) \\
\hline $3.08 \pm 0.368$ & $0.0083 \pm 0.0011$ \\
\hline
\end{tabular}

\section{ACKNOWLEDGEMENTS}

The authors wish to express sincere thanks to the former faculty and chairman (Head of the Department), Department of Animal Science, Darab branch, Islamic Azad University, Darab, Fars, Iran and Herbal Medicine Research Center, Bandar abbas, Iran for extending the laboratory facilities to carry out the research work.

\section{CONTRibution OF AUTHORS}

The authors declare that this work was done by the authors named in this article and all liabilities pertaining to claims relating to the content of this article will be borne by them.

\section{REFERENCES}

[1] Khajeh M, Yamini Y, Sefidkon F, Bahramifar N. Comparison of essential oil composition of Carumcopticum obtained by supercritical carbon dioxide extraction and hydrodistillation methods, Food Chemistry, 2004; 86: 587-591.

[2] Golmakani MT, Rezaei K. Microwave-assisted hydrodistillation of essential oil from Zatariamultiflora Boiss, Eur. J. Lipid Sci. Technol, 2008; 110: 448-454

[3] Lucchesi ME, Smadja j, Bradshaw S, Louw W, Chemat F. Solvent free microwave extraction of Elletaria cardamomum L: A multivariate study of a new technique for the extraction of essential oil. J. Food Eng, 2007; 79: 1079-1086.

[4] Lucchesi ME, Chemat F, Smadja J. Solvent-free microwave extraction of essential oil from aromatic herbs: comparison with conventional hydro-distillation. J. Chromatogr A, 2004; 1043: 323-327.

[5] Hajimehdipoor H, Samadi N, Mozaffarian V, Rahimifard N, ShoeibiSh M, Pirali Hamedani. Chemical composition and antimicrobial activity of Oliveria decumbens volatile oil from west of Iran. J. Med. Plants, 2010; 9(6): 39-44.

[6] Ghahraman A, Attar F. Biodiversity of plant species in Iran. Tehran: Tehran University Press, 1998.

[7] Olle M, Bender I. The content of oils in umbelliferous crops and its formation, Agronomy Research, 2010; 8(3): 687-696

[8] Mozffarian V. A dictionary of Iranian plant names, Tehran, Iran: Farhang Moaser, 1996.

[9] Sadraei HG, Asghari A, Naddafi. Relaxant Effect of essential oil and hydro-alcoholic extract of Pycnocyclaspinosa Decne. ExBoiss. On Ileum Contractions, Phytother. Res, 2003; 17: 645-649 
[10] Negahban M, Moharramipour S, Sefidkon F. Fumigant toxicity of essential oil from Artemisia sieberi Besser against three stored product insects. J. Stored. Prod. Res, 2007; 43: 123-128

[11] Adams RP. Identification of essential oil components by gas chromatography/mass spectroscopy, Allured Publishing Co, Carol Stream, IL, 2007; p-804.

[12] Safaei-ghomi J, Meshkatalsadat MH, Nano scale injection for the determination of volatile organic components of vitex pseudo-negundo using various extraction techniques, Digest journal of nanomaterials and biostructures, 2010; 5(1): 207-213

[13] Morteza-semnani K, Saeedi m, Akbarzadeh M. Sastav eteri noguljabiljke Teucriumscordium L. Acta Pharm, 2007; 499-504.

[14] König WA, Hochmunth DH, Joulain D. Terpenoids and related constituents of essential oils. Mass finder 2.1, Hamburg, Germany, 2001.

[15] Murray PR, Baron EJ, Pfaller MA, Tenover FC, Yolke RH, Manual of clinical microbiology $\left(7^{\text {th }}\right.$ Ed.). USA, Washington, DC: ASM, 1995; pp 264-282.

[16] NCCLS-National Committee for Clinical Laboratory Standards. Performance standards for antimicrobial susceptibility testing: $11^{\text {th }}$ informational supplement, Document M100-S11, National Committee for Clinical Laboratory Standard, Wayne, PA, USA, 2003.

[17] Chen H, Yang, Y, Xue J, Wei J, Zhang Z, Chen H. Comparison of compositions and antimicrobial activities of essential oils from chemically stimulated agarwood, Wild Agarwood and Healthy Aquilariasinensis (Lour.) Gilg Trees, Molecules, 2011; 16: 4884-4896.

[18] Stojkovic D, Sokovic M, Glamoc `lija J, Džamic A, Iric A, Ristic M, Grubišic, D. Chemical composition and antimicrobial activity of Vitexagnus-castus L. fruits and leaves essential oils, Food Chemistry, 2011; 1017-1022.

[19] Brand-Williams W, Cuvelier ME, Berset C. Use of free radical method to evaluate antioxidant activity. Lebensmittel-Wissenschaft \& Technologie, 1995; 28: 25-30.

[20] Bouzidia E, AlaouiJamalia Ch, Bekkouche K, Hassani L, Wohlmuth H, Leache D, Abbada A. Chemical composition, antioxidant and antimicrobial activities of essential oils obtained from wild and cultivated Moroccan Thymus species, Industrial Crops and Products, 2013; 450-456

[21] Salehi P, Sonboli A, Eftekhar F, Nejad-ebrahimi S, Yousefzadi M. Essential Oil Composition, antibacterial and antioxidant activity of the oil and various extracts of Ziziphora Clinopodioides subsp. rigida (BOISS.) Rech. f from Iran, Biol. Pharm. Bull, 2005; 28(10): 1892-1896

[22] Chandler SF, Dodds JH. The effect of phosphate, nitrogen and sucrose on the production of phenolics and solasidine in callus cultures of Solanumlacinitum. Plant Cell Rep, 1983; 2: 105108.

[23] Slinkard K, Singleton VL. Total phenol analyses: automation and comparison with manual methods. Am. J. Enol. Vitic, 1977; 28: 49-55.

[24] Alizadeh A, Khoshkhui M, Javidnia K, Firuzi OR, Tafazoli E, Khalighi A. Effects of fertilizer on yield, essential oil composition, total phenolic content and antioxidant activity in Satureja hortensis L. (Lamiaceae) cultivated in Iran, Journal of Medicinal Plants Research, 2010; 4(1): $33-40$.

[25] Farjam MH, Talebi E, Shivkumar, Nasrollahi I. Chemical constituent, antimicrobial and antioxidant activities of Anvillea garcini an essential oil plant, International journal of pharmaceutical research and bio-science, 2015; 4(2): 215-224.

[26] Asghari G, Jalali M, Sadoughi E. Antimicrobial activity and chemical composition of essential oil from the seeds of artemisia aucheri Boiss, Jundishapur J Nat Pharm Prod, 2012; 7(1): 11-15

[27] Huang HC, Chang TY, Chang LZ, Wang HF, Yih WY, Chang TM. Inhibition of melanogenesis versus antioxidant properties of essential oil extracted from leaves of Vitexnegundo Linn and chemical Composition analysis by GC-MS, Molecules, 2012; 17: 3902-3916.

[28] Farjam MH, Khalili M, Rustayian A, Javidnia K, Izadi S. Biological activity of the n-butanolic extract of Stachyspilifera, African Journal of Microbiology Research, 2011; 5(28): 5115-5119.

[29] Talebi E, Shivkumar, Nasrollahi I. Quantitative estimation of total phenolic contents of the essential oil- "anvillea garcini" through the hydrodistilation, world journal of pharmacy and pharmaceutical sciences, 2015; 4(5): 185-189. 